\title{
EL ROL DE LAS UANGUARDIAS ARTISTICAS EN LA CONSTRUCCIÓN DE LOS PRINCIPIOS DEL DISEÑO EDITORIAL
}

Gisela L. ROSENTAL. ketchuprcia@gmail.com

Estudiante de cuarto año de la carrera Diseño Gráfico, adscripta de la materia Historia II

PALABRAS CLAUE

Diseño editorial, conceptos básicos, siglo XX.

\section{RESUMEN}

Existen en el campo del diseño editorial ciertos conceptos o nociones básicas que estructuran el quehacer diario del diseñador, la construcción de grillas, la legibilidad, los criterios de selección tipográfica, aspectos compositivos, entre otros detalles, que tienen su base en el desarrollo editorial del siglo XX. Por esto mismo la propuesta radica en realizar una revisión de los movimientos más influyentes de las primeras décadas, evaluar las condiciones en las que se dio el diseño editorial y los aportes realizados por dichos movimientos en el campo. También se propone reflexionar sobre los contextos histórico-sociales de cada uno de dichos cambios, a fin de comprender la lógica que lleva a desarrollarlos y entender su aplicación.

\section{KEYWORDS}

Editorial design; basic concepts; twentieth century

\section{ABSTRACT}

There are in the field of editorial design certain concepts or basic notions that structure the daily work of the designer, the construction of grids, readability, typesetting criteria, compositional aspects, among other details, which are based on the editorial development of the twentieth century. For this reason the proposal is to make a revision of the most influential movements of the first decades, to evaluate the conditions in which the editorial design and the contributions made by said movements in the field were given. It is also proposed to reflect on the historical-social contexts of each of these changes, in order to understand the logic that leads them to develop and understand their application. 


\section{OBJETIUOS}

- Profundizar en el origen de los conceptos básicos que rigen el diseño editorial actualmente.

- Comprendersudesarrolloy evolución, conocersulógica y cómo llegan a resultar tan influyentes en la disciplina en la actualidad.

- Plantear una visión crítica sobre el peso de dichos conceptosyelsentido de dichas nocionesen función de la comunicaciónylaevolución del diseño editorial.

\section{INTRODUCCIÓN}

A lo largo de la formación que brinda la carrera de Diseño Gráfico, la producción editorial es en mayor o menor medida un elemento omnipresente. Este fue el medio más elegido en el transcurso de la historia para manifestarideas, promoverlas y hacerlas perdurar.

Desde los principios de la escritura, el conocimiento fue sinónimo de grandeza, de poder y en gran medida un lujo para unos pocos; pero la historia del libro da un vuelco enorme con la aparición de la imprenta de tipos móviles. El libro como símbolo de estatus, sabiduría y poder se vuelve más accesible, la producción delibrossehace masiva y se amplía su llegada. Aun así, el conocimientoseguía estandoreservado para quien pudiera costearlo; solamente la clase más alta tenía acceso a los libros de forma regular.

Con la llegada de las dos grandes revoluciones (política e industrial), el papel del libro en la historia volvió a cambiar: ahora las ideas eran del pueblo y para el pueblo; por lo tanto, debían llegar a él de manera más rápida y efectiva. La producción industrial de libros abarató en gran medida los costos y los volvió más accesibles, les dio una llegada más amplia y popularizó el saber.

Así es como llegamos a principios del siglo $X X$, con una sociedad en transición, en plenocambio de ideales, en constante movimiento; una sociedad condicionada por la violencia, azotada por las guerras. La primeramitad del siglosecaracteriza por haber pasado por los procesos políticosmás radicalesy las guerras másviolentas, quecomenzaroncon la Primera Guerra Mundial en 1914. Esta fue conocida como "guerra mundial" debido a la magnitud de sualcance, la multitud de potencias mundialesinvolucradasenelconflicto y los terribles daños provocados por esta catástrofe.

Mientras la guerra revolucionaba a toda Europa, en Rusia se podían ver cada vez más claramente las falencias del régimenzarista. Lainutilidad del modelo políticoy económico, la pobreza desmedida, la opresión, la desaparición de todo tipo de opositores, la violencia generalizada y la visible falta de libertad hicieron que el pueblo tomara las armas y se rebelaraanteel gobiernoautoritario, con una sangrienta ola de violencia. De esta revolución surgió la nueva Rusia, caracterizada poruna política comunista y un pueblo comprometido, activo y atento a saciar todas sus necesidades.

La caída de los valorestradicionales que caracterizaban al mundo, la visible falta de equidad y justicia, la ausencia de estabilidad y la creciente revalorización de la libertad caracterizaron el arte y el diseño en este momento. A la búsqueda de nuevos valores, de unificación, de establecer nuevos parámetros útilesparatodos, universalesyclaros responde la investigación, experimentación y producción de los primerosañosdeestamitaddelsiglo. Aquies donde se ubica la investigación, este es el momento histórico en el que se construyen las bases de los conceptos más esenciales del diseño editorial, que aplicamos hasta hoy en día. Conceptos que trascendieron décadas y paradigmas por su claridad, efectividad y su profundísimo estudio. 


\section{DESARROLLO}

La primera vanguardia que estudiar comienza con la publicación del manifiesto futurista en el diario italiano /l Figaro, escrita por el poeta FILIPPO MarINETTI en 1909. En el manifiesto reza: "Proponemos celebrar el amor al peligro, la costumbre de la energíay la intrepidez. Valor, audacia y rebelión serán los elementos esenciales de nuestra poesia" (MegGs, 1991:301). Además de esto, el movimiento se propone expresar la situación del hombre en ese momento cargado de enormes cambios como los avances tecnológicos y la creciente presencia de maquinarias en la vida diaria, que lentamente la alterarían y acelerarían su ritmo en gran medida. Así lo expresan en el manifiesto: "Afirmamos que la magnificencia del mundo ha sido enriquecido con una nueva belleza: la belleza de la velocidad... Excepto en la lucha, no hay belleza" (MegGs, 1991: 301). Podemos observar todo este contenido en su prolífica producción que incluye dibujo, pintura y productos editoriales.

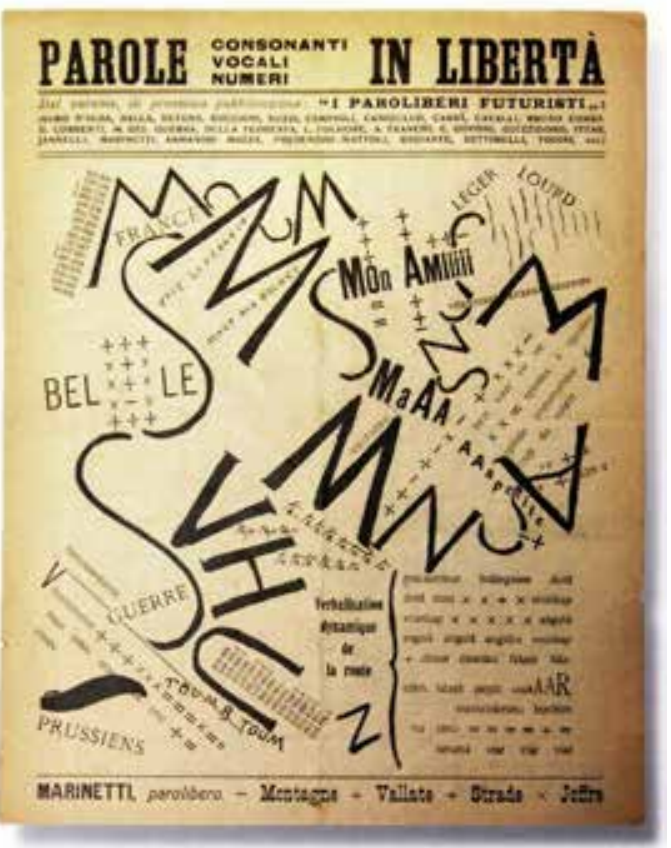

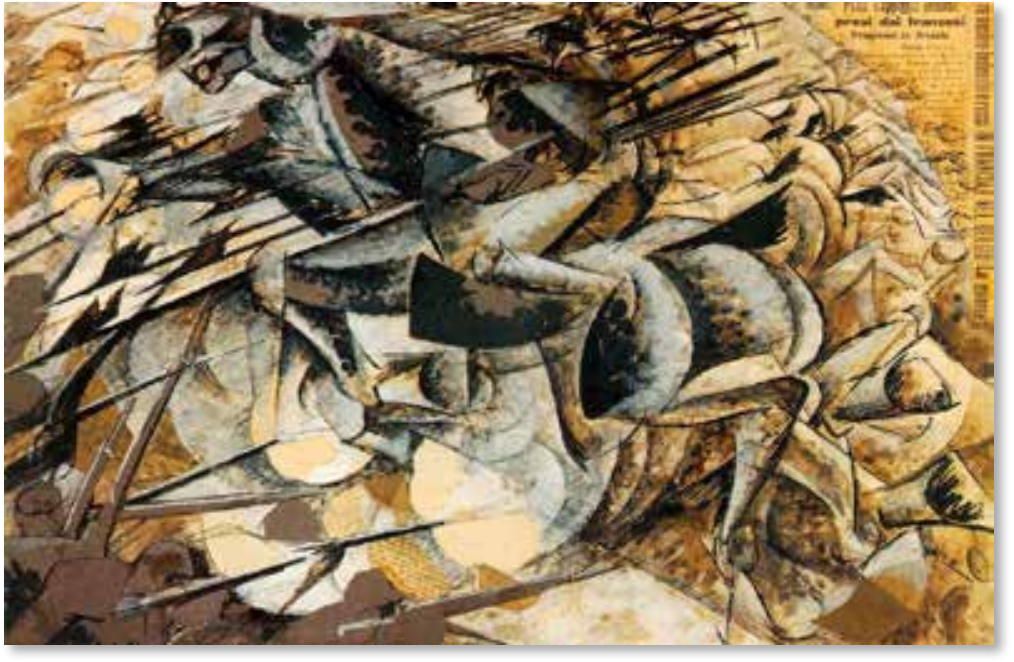
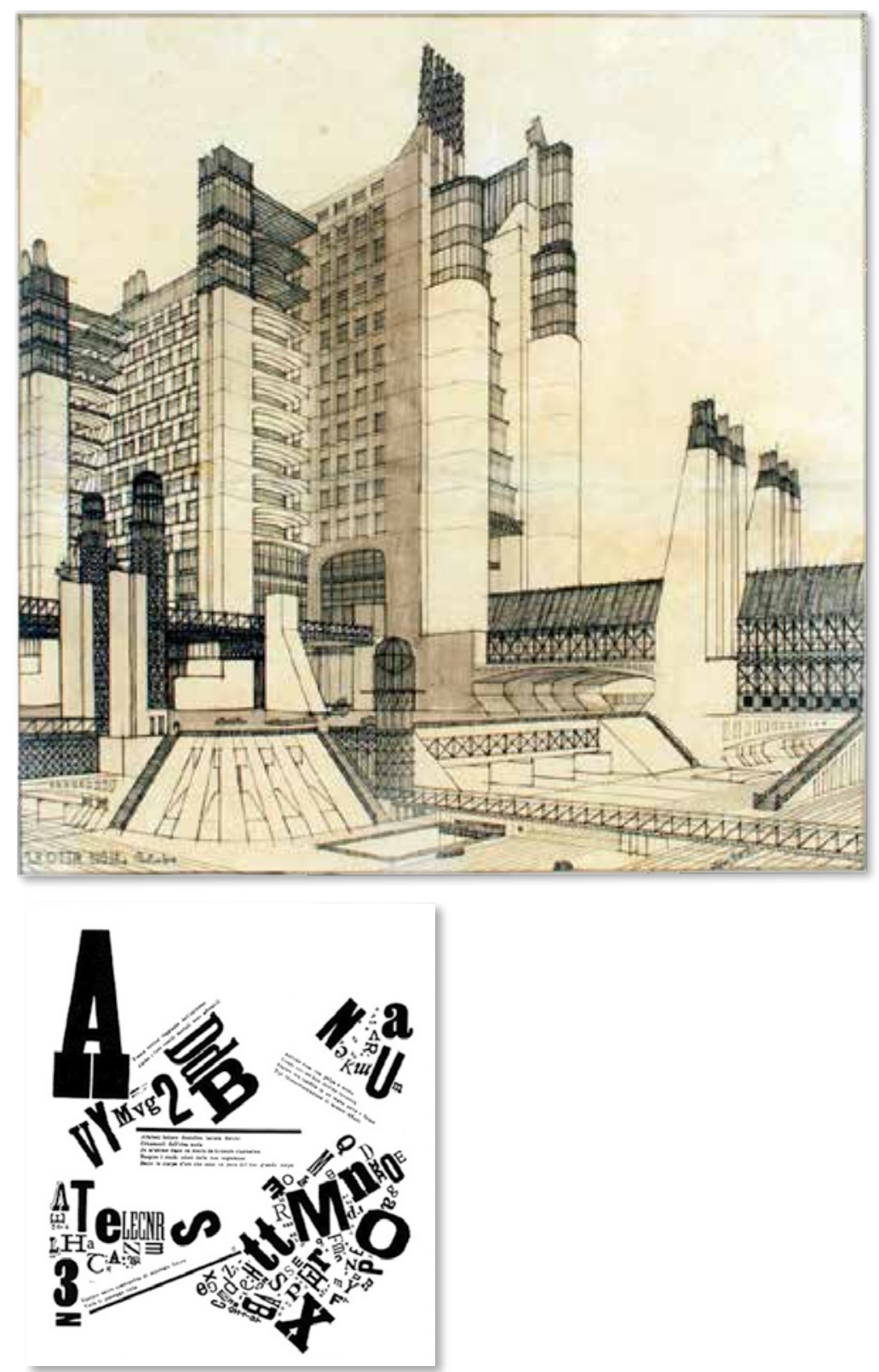
Dado el enfoque de la investigación, solo haremos hincapié en la producción editorial y de poemas visuales, la cual analizaremos en profundidad. Los futuristas se opusieron a todo lo previamente establecido, incluso a la forma de plasmar un texto en la página, y crearon sus propias reglas. Como explica Herbert Spencer: "Estoy en contra de lo que se conoce como armonía de una composición. Cuando sea necesario utilizaremos tres o cuatro columnas por página $y$ veinte tipos distintos. Representaremos percepciones irreflexivas en cursiva y expresaremos un grito en negrita" (1990: 17). La poesía futurista también se caracterizó por generar formas de organizar la tipografía que reforzarán su expresividad. Analizaremos esto en las siguientes imágenes.
En la primera pieza es posible observar claramente la función de la tipografía como vehículo expresivo, los pesos visuales que genera, los diversos tamaños, variables y la repetición resuelven gráficamente las situaciones auditivas de intensidad, volumen, tipo de sonido o secuencias. La posición diagonal, el reescalado y el cambio de caja baja a caja alta nos sugieren que el sonido se está intensificando a medida que ingresa en el campo, que es un sonido que se corta y repite en lugar de ser un sonido único, y que cada pequeña repetición se prolonga un poco. Este tipo de resoluciones nos demuestran cómo la tipografía puede tomar una posición de interpretación, en la que el concepto representado se perciba incluso antes que la palabra y permita la comunicación más inmediata de la idea.

En esta segunda pieza es posible observar - siguiendo con la idea anterior deque la tipografía comunique el concepto independientemente de su contenido literario- una nueva escala de la propuesta. En los poemas futuristas, la tipografía se desprende del renglón, abandona la convencionalidad para adoptar una forma que exprese su real contenido. Este tipo de decisiones permite vincular de forma inmediata la forma visual con el contenido del poema. Este criterio se repite en una múltiple cantidad de obras del repertorio futurista.

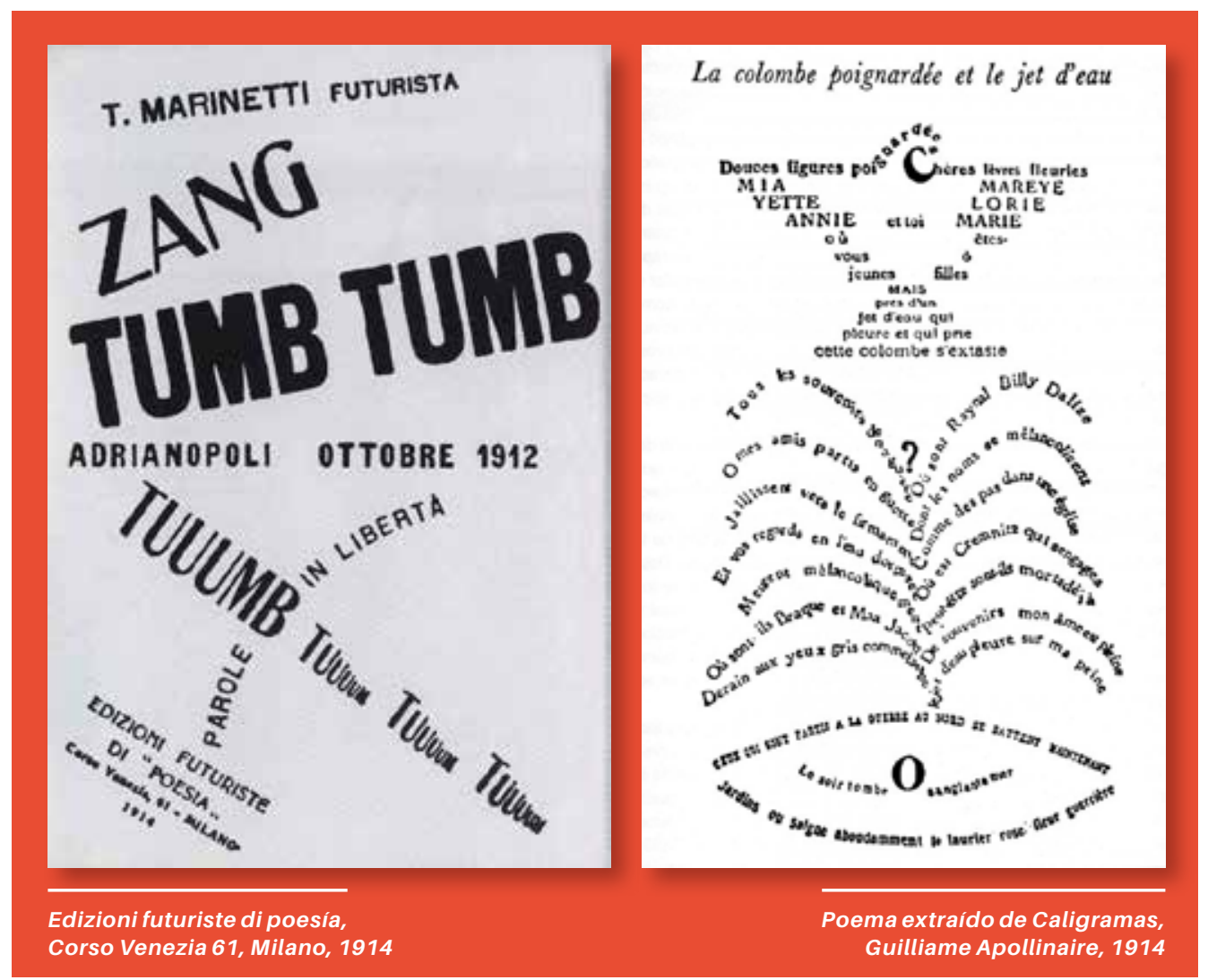


La siguiente vanguardia tiene una fuerte relación con el futurismo, ya que, como comenta Spencer, después de publicado, el manifiesto se expandió rápidamente hacia el este y generó un gran impacto. viajó a Moscú en 1914 para dar una conferencia, el futurismo ya estaba asentado en la ciudad. En Rusia, a principios del siglo $X X$, se vivía una situación de tensión política muy fuerte. El gobierno del zar estaba llegando a su fin y la presión que se ejercía sobre el pueblo, las carencias existentes, tanto de alimento como de instrucción, junto con la falta de libertad pueden haber sido las su expresividad y libertad, se haya asentado con tanta fuerza.

Durante este período de exasperación y represión surge en Rusia una vanguardia artística llamada suprematismo, basada en el uso de figuras abstractas como medio expresivo y en menor medida de tipografía utilizada de una forma muy característica. Después de la Tanto es así que cuando MarinetTI razones por las que el futurismo, con
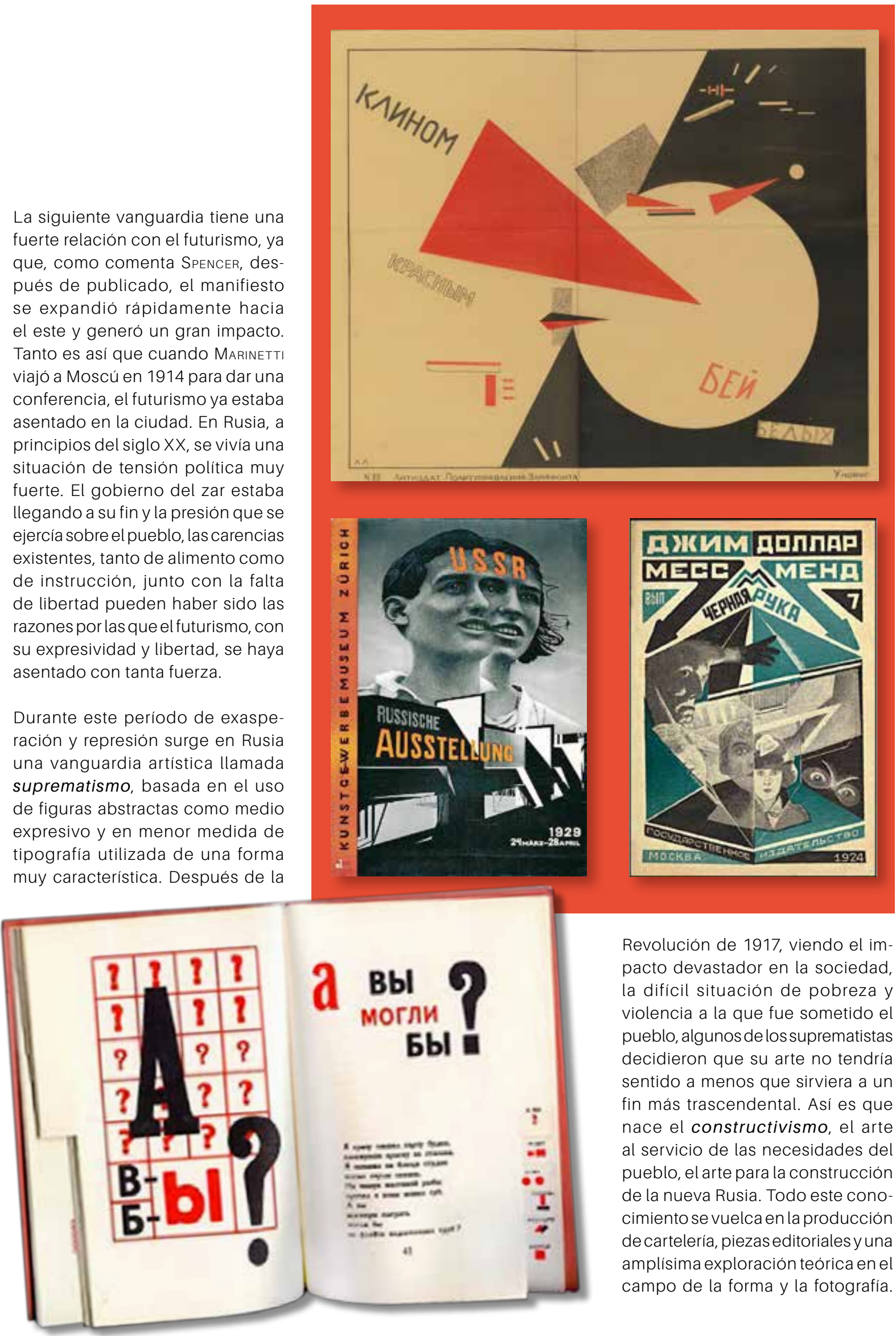

Revolución de 1917, viendo el impacto devastador en la sociedad, la difícil situación de pobreza y violencia a la que fue sometido el pueblo, algunos de los suprematistas decidieron que su arte no tendría sentido a menos que sirviera a un fin más trascendental. Así es que nace el constructivismo, el arte al servicio de las necesidades del pueblo, el arte para la construcción de la nueva Rusia. Todo este conocimiento se vuelca en la producción de cartelería, piezas editoriales y una amplísima exploración teórica en el campo de la forma y la fotografía. 
El constructivismo le dio al diseño gráfico un pensamiento ordenado. Primero es preciso conocer al público y luego diseñar para él, basándose en sus necesidades. Con conciencia de que la mayoría del público era analfabeta, su desarrollo en la cartelería proponía una escasa cantidad de texto (solo lo necesario), compuesta por una tipografía sans serif, de modo que el ornamento de la tipografía no dificultara el reconocimiento de los caracteres y por ende la lectura, considerando la dificultad que ya representaba para el usuario. Esta decisión estaba acompañada por el uso de imágenes muy fuertes, pregnantes y claras; de este modo, aunque el receptor no pudiera leer el mensaje escrito, lo podía comprender a través de la imagen.

A la hora de construir piezas editoriales, el constructivismo se encargó de organizar todo de la forma más exacta posible. Un gran ejemplo es el Libro de los Ismos del Arte; alli podemos ver una clara división en los paquetes de información, la separación de títulos y subtítulos, el

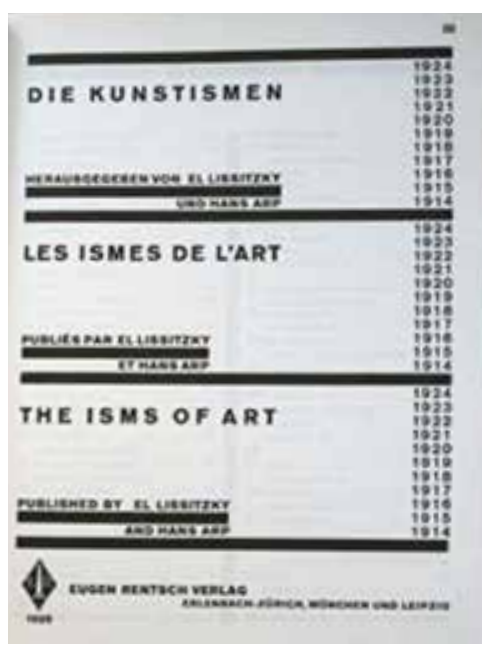

Los Ismos del arte, El Lissitzky, 1929. es muy importante (tanto en este caso como en el desarrollo interior de la publicación), ya que le da al lector la pauta que determina dónde buscar la información de acuerdo con el idioma que maneje. En esta publicación se observan dos tipologías de página distintas, una estructurada de acuerdo con los idiomas que maneja y otra que posee una estructura más unificada. En la primera imagen se mantiene una estructura similar al desarrollo de Los Ismos del Arte. Cuenta con tres columnas (una por idioma), pero a diferencia del anterior, aquí es posible observar muchos tipos de información, destacados en mayúsculas, subtítulos, y otro espesor en las líneas guía. Si se observa con atención la estructura de la página, a diferencia del caso anterior, el campo está dividido en dos partes de manera horizontal (una franja ligeramente menor arriba y otra

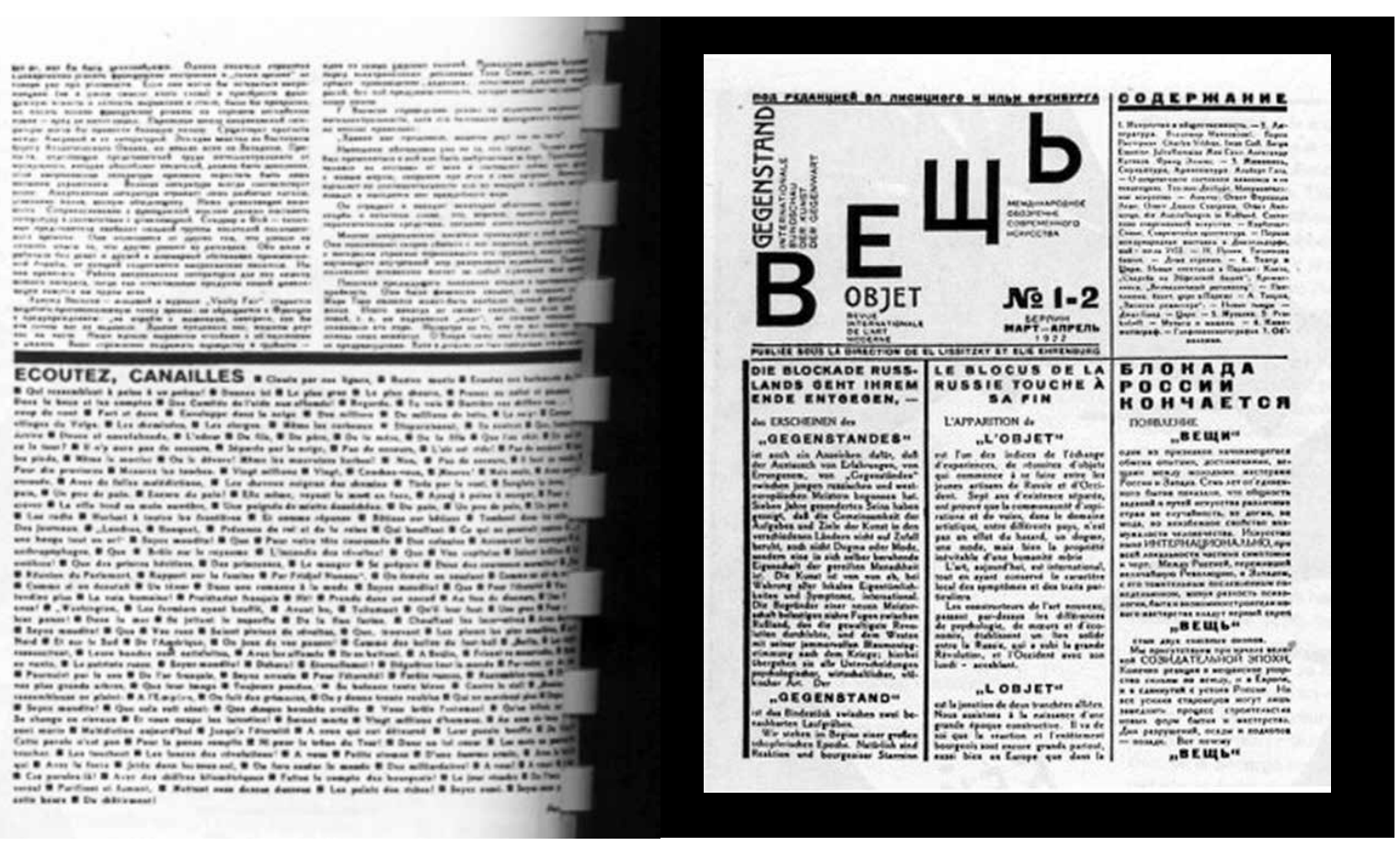


mayor por debajo) y en tres partes de forma vertical, correspondientes a la división de idiomas. En el bloque superior de la página se encuentra la imagen de las tapas de antiguas revistas y, a su lado, una amplia caja de texto en idioma ruso.Por su ubicación y presentación, se entiende que esta información es distinta de la que se encuentra organizada en bloques verticales. Respecto de la segunda imagen, se observa nuevamente una división que combina los bloques verticales y horizontales haciendo un énfasis mucho mayor en la horizontalidad, tanto por el uso de una línea divisoria como por la diferencia en el uso de las cajas de texto, que arriba funcionan como dos columnas, mientras que abajo presenta solo una gran caja. Esta página permite una rápida identificación de los paquetes de información, ya que un paquete está trabajado en variable bold, y el otro en variable regular.

En esta pieza existe una fuerte fusión entre el futurismo y el constructivismo. Presenta la construcción de imágenes a través de la tipografía y las lleva a ocupar tres cuartas partes de la página; esto nos habla de la jerarquía que merece este contenido y la forma en que debe ser leído. Esta imagen debe ser leída en un solo vistazo, como si fuera un cartel que en caso de buscar una lectura más profunda, debe ser releída con mayor detenimiento. Existe una cantidad escasa de texto, y cuando está presente, se ubica en el centro de la página, por debajo de la imagen. Otra razón por la cual este es un gran ejemplo es la aparición del paginado (o posiblemente, su antecesor), que está propuesto a través de un corte en el margen lateral externo, donde se imprime un signo que identifica a la página. Esto permite al usuario relacionar el signo con cada poema una vez explorado el libro.

Mientras en Italia el futurismo se alimentaba de la energía, la adrenalina y la violencia generada por

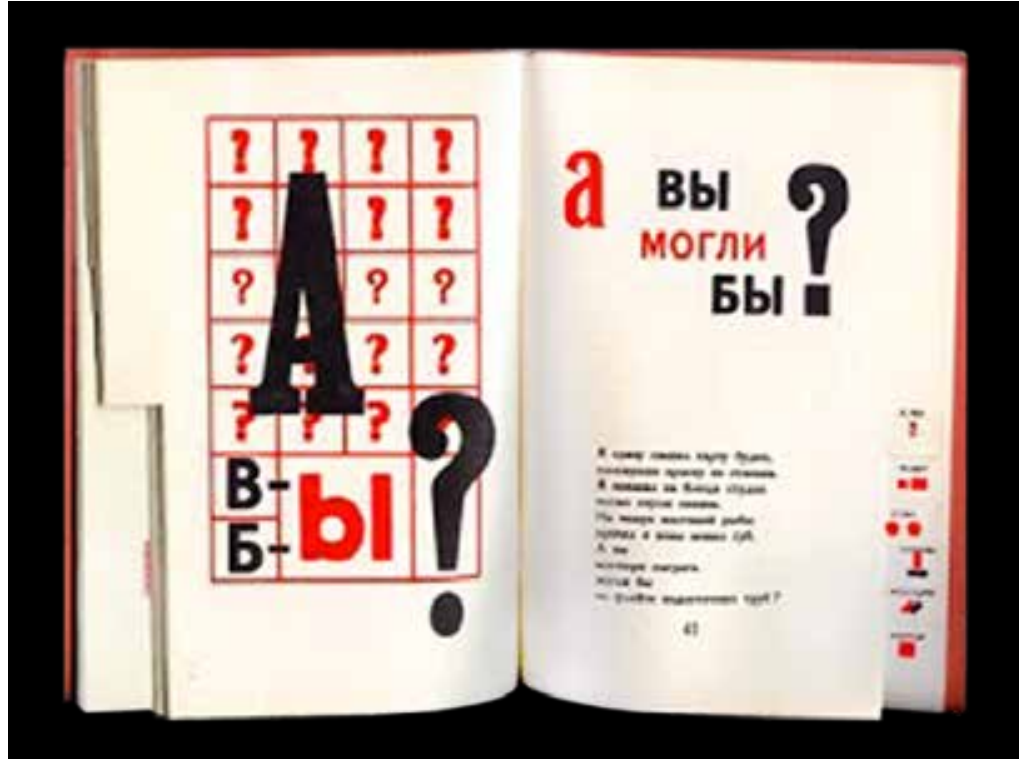

Revista Vesch, El Lissitzky, 1922

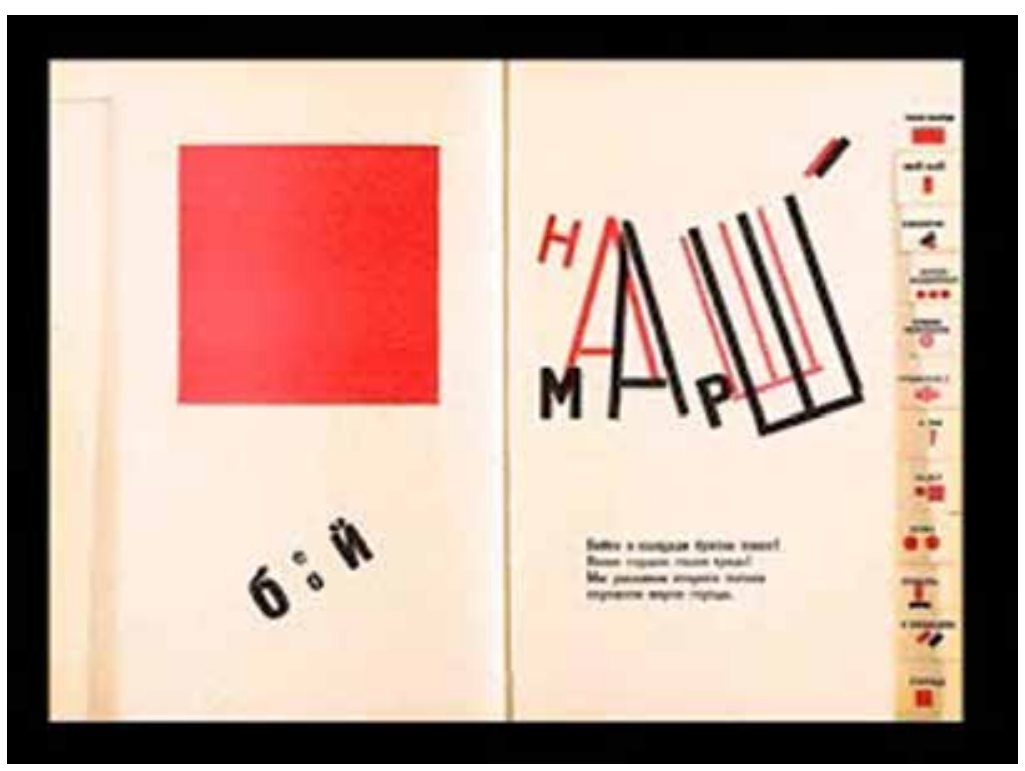

Por la voz de Maiakovsky, El Lissitzky, 1923.

el clima precedente a la Primera Guerra Mundial, en Zúrich el dadaísmo se oponía totalmente a esto. El dadaísmo "nació de la desilusión provocada porlaguerray la repugnancia por la matanza de millones de personas en los campos de batalla enemigos" (SPENCER, 1990: 21). Toda esta violencia que envuelve al movimiento generó en ellos una fortísima rebelión: "Afirmaban ser el anti arte y poseía un fuerte elemento destructivo y negativo. Rechazando toda tradición, el dadaísmo buscó la libertad total" (MegGs, 1991: 308). Este movimiento estaba cargado de bronca, ironía y un tono burlesco que atacaba directamente a la sociedad europea, sus valores, la frivolidad, los códigos morales y la hipocresía. Esta corriente manifiesta su punto de vista a través de distintas propuestas: carteles, piezas editoriales, fotografías y escultura, y alcanza una enorme producción admirada hasta hoy en día, a pesar de la increíble contradicción que esto genera. 

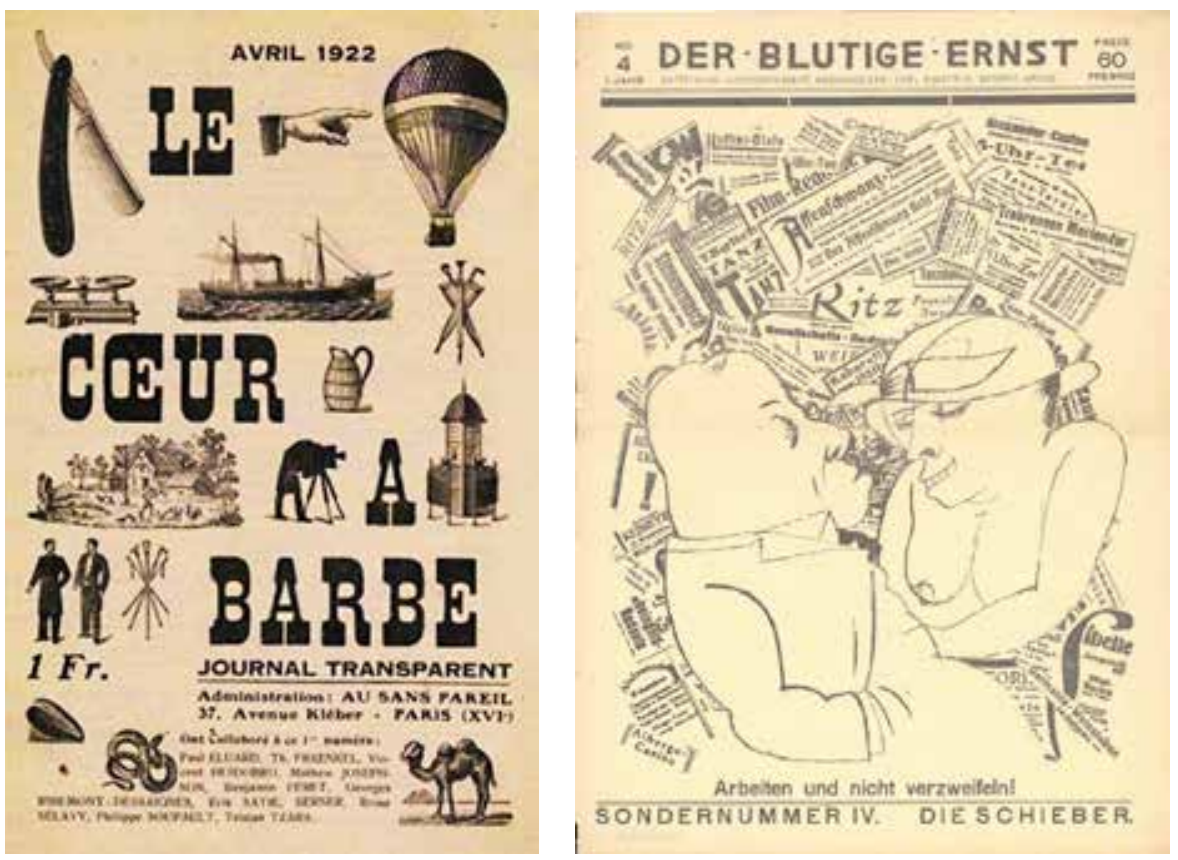

Para plasmar estos valores, el dadaísmo se valió de múltiples herramientas. A la hora de construir imágenes trabajó con diversas técnicas, como el rayonismo, la experimentación fotográfica y el collage, siendo este último el lenguaje predilecto. Sus composiciones están llenas de mensajes fuertes, perspicacia y una gran complicidad con el lector. En relación con lo tipográfico, continúan con la idea futurista de despegar la tipografía del renglón; también retoman las investigaciones expresivas de este movimiento, pero deciden llevarlas al extremo utilizando múltiples familias y variables tipográficas (de peso, extensión, inclinación, caja, etc.), a las que se aplican operaciones morfológicas y con ellas se construyen puestas enteras. También se valieron de signos auxiliares, como líneas, manos indicadoras, flechas e ilustraciones variadas.

En estas páginas podemos observar que el sinsentido que atraviesa la producción dadaísta se encuentra repentinamente con el orden y la legibilidad requeridos en una pieza editorial. Como resultado de esta unión se presentan dos páginas de la revista Merz, una donde las cajas de texto se encuentran giradas en forma
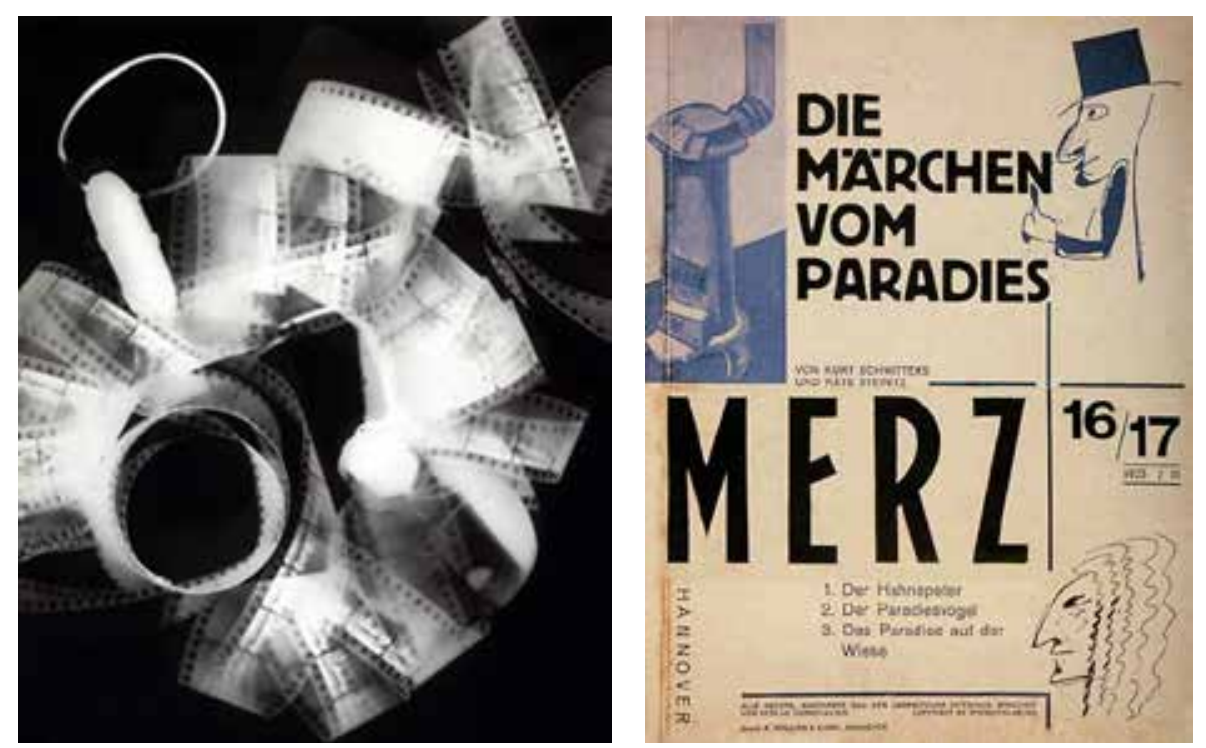

vertical, pero la escritura dentro de ellas mantiene su sentido, mientras que en la siguiente página las cajas mantienen el sentido tradicional y se incorporan imágenes. Ambas tienen un particular paginado en el margen superior, que si bien no responde a un código de familia o de peso similares, su ubicación en la página (que aun asívaría ligeramente) indica que responden a un mismo tipo de información. En ambas páginas se pueden identificar de forma clara los paquetes de información, pero en la segunda, al contener mayor cantidad de variables (de peso y caja) resultan más claramente identificables. Otra cuestión que comparten ambas páginas es un margen superior muy generoso, a diferencia del resto de los márgenes, que en la primera página son mucho más amplios.

En esta página, Merz presenta una gran innovación, una situación de doble página en la que el contenido 


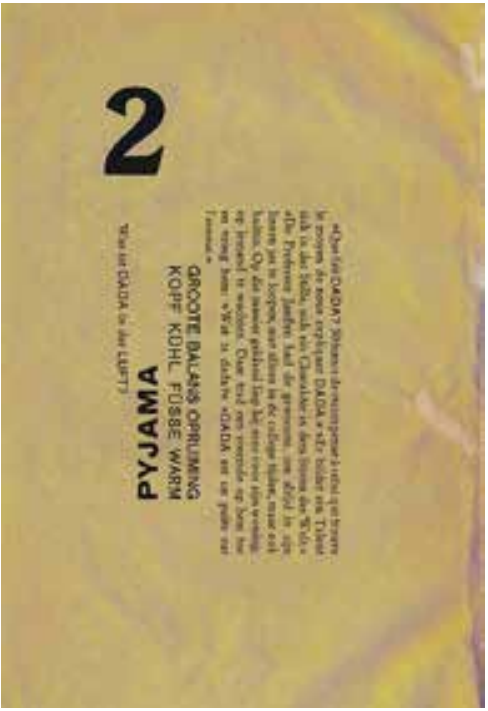

compartido porambasesuna imagen central de gran tamaño, que está acompañada por múltiples cajas de texto. En esta página se retoma la idea de alterar la orientación de algunas cajas de texto, para generar más de una forma de interactuar con la pieza. Si bien aquí los paquetes de información se distinguen claramente, ya no presenta tantas variables de tamaño y peso como en otros casos. Trabaja con íconos, pero les otorga sentido y coherencia; estos sirven para indicar la jerarquía de un elemento dentro de la página, ya que su ausencia modificaría la forma de comprenderlos.

Aquí coexisten una gran variedad de elementos tipográficos que operan en distintos tamaños y variables y generan contrastes muy marcados, pero que gracias a su ubicación dentro del campo no resultan confusos respecto de su jerarquía. Esta tapa cuenta con la inclusión de una imagen fotográfica, y si bien esta es una decisión que se replica en varios números posteriores de la revista, hasta el momento no tenía precedentes. Trabaja con una variedad de cajas de texto que, a pesar de utilizar un cuerpo tipográfico similar, se distinguen como información diferente debido al ancho de caja con el que fueron trabajadas. La estructura de la página está notablemente reforzada por las líneas

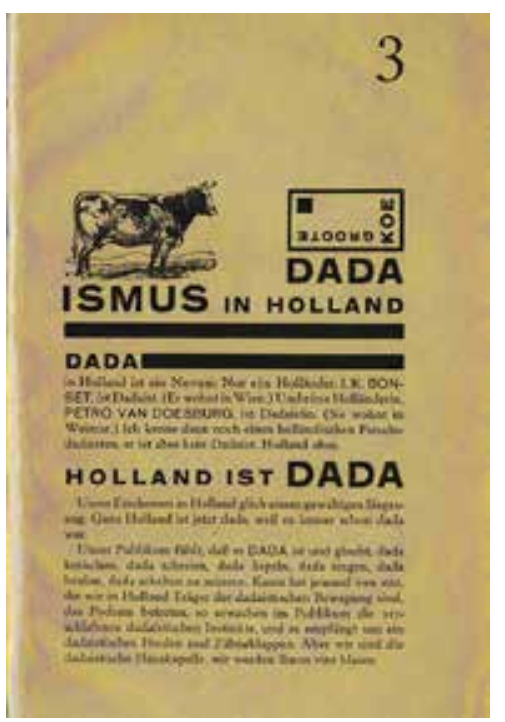

Revista Merz N. ${ }^{1}$, Kurt Schwitters, 1923

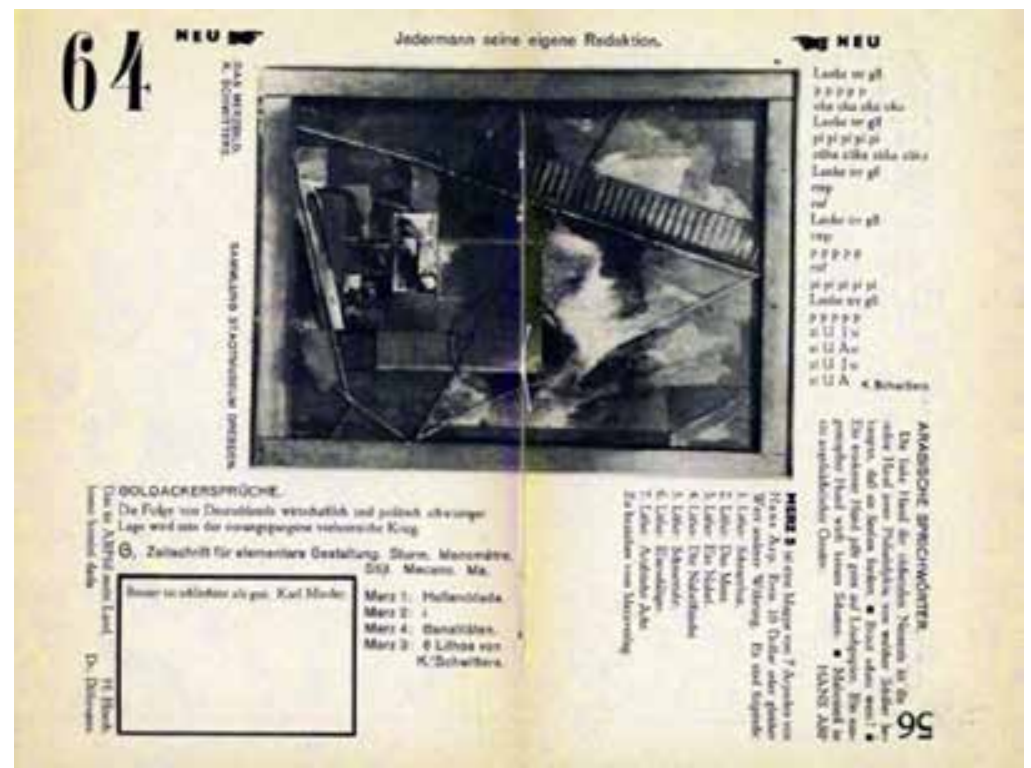

que presenta; pese a estas separaciones puede comprenderse como una estructura muy equilibrada, y dependiendo de la forma en que se la observe puede resultar fuertemente vertical (a causa de la marcada zona que generan todos los elementos que se encuentran sobre el extremo derecho) o claramente horizontal (por las líneas visuales que genera la caja de texto que atraviesa la página de margen a margen y las palabras ubicadas sobre el margen inferior).

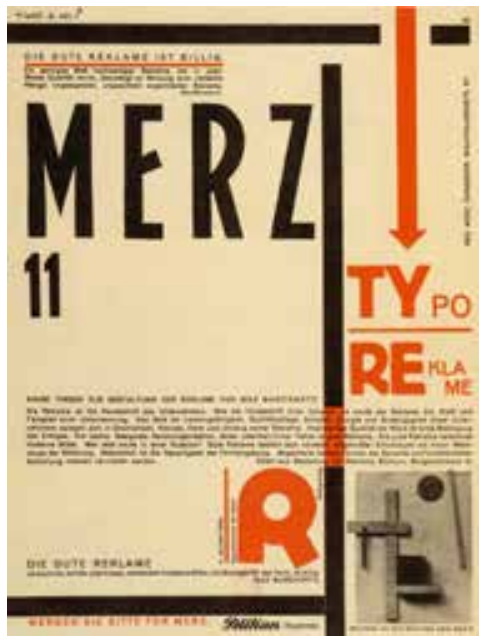

Revista Merz N. ${ }^{\circ}$ 11, Kurt Schwitters, 1924
Revista Merz N. ${ }^{\circ} 6$, Kurt Schwitters, 1923 
Revista Merz N ${ }^{\circ} 11$ Kurt Schwitters, 1924

Esta portada presenta una puesta íntegramente tipográfica, solamente acompañada porlíneasymisceláneas. Sibien utiliza una cantidad medida de familias y variables de peso, logra una precisa diferencia entre tipos de información gracias al manejo del cuerpo tipográfico y la aplicación muy específica del color. La estructura de la pieza en este caso es completamente independiente de la orientación de las líneas; de no existir estas, la estructura sería aún más evidente. La página se fracciona en dos porciones de forma horizontaly dosen forma vertical. Al corte que generan las dos franjas horizontales se lo puede identificar a través de la bajada que acompaña el título; a partir de ella y hacia arriba se encuentra una franja, desde su final y hacia abajo se puede ver otro espacio. Dentro de este espacio es donde se hace visible la fracción vertical; existe una zona más angosta hacia la izquierda determinada por la caja de texto en posición vertical y una zona más ancha, marcada por la caja de texto de orientación horizontal y color rojo.

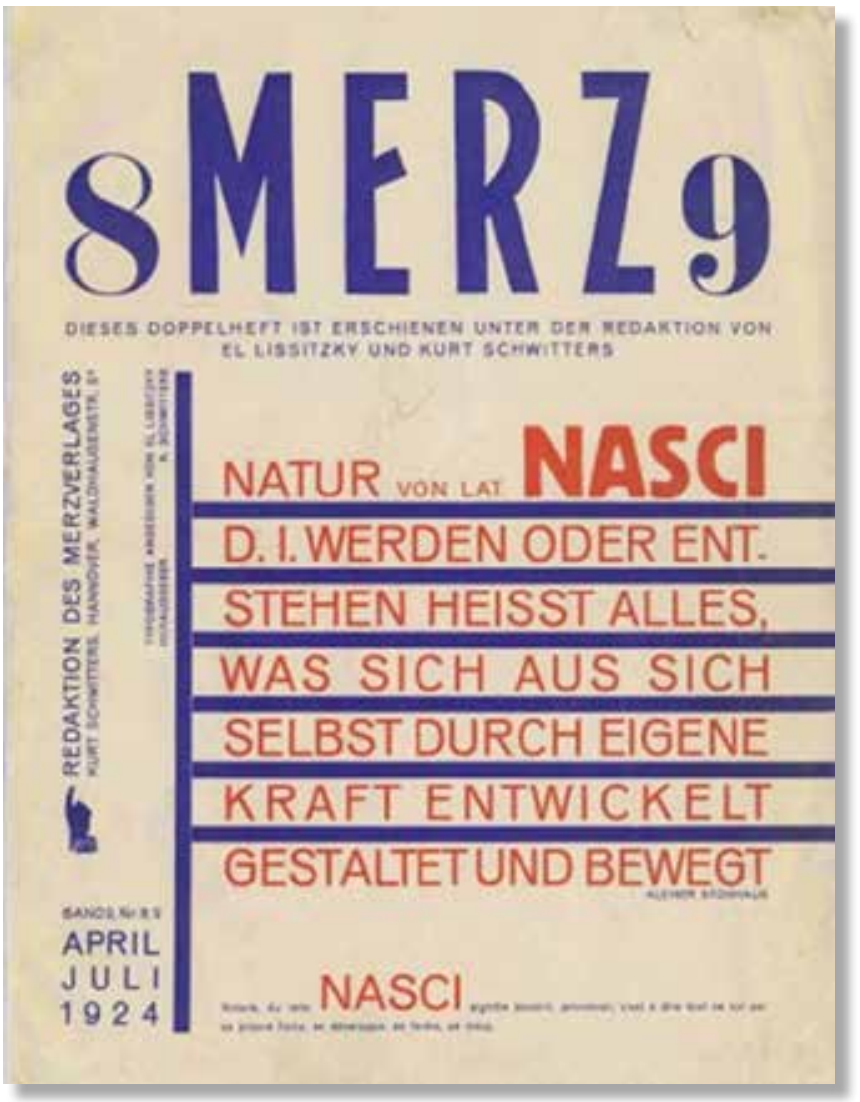

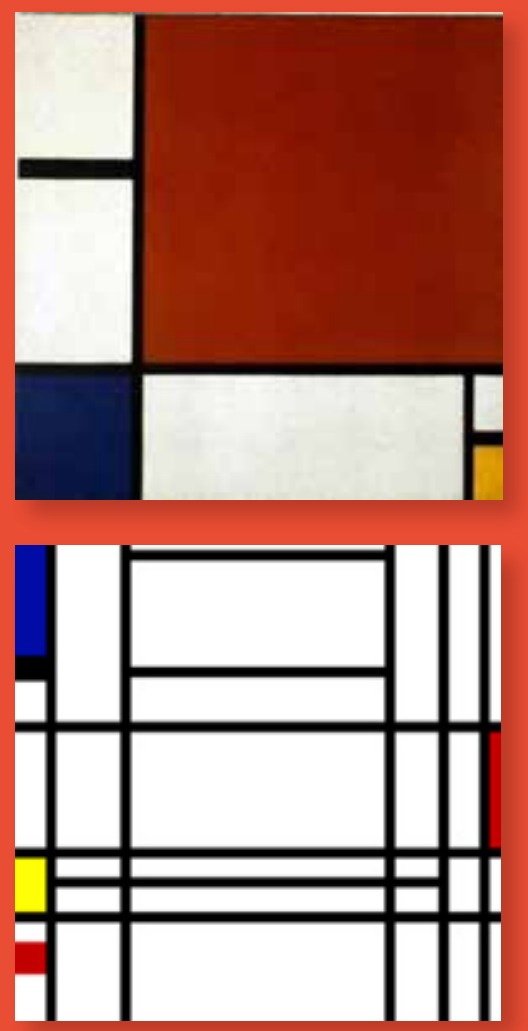

Otro movimiento sumamente influyente para el diseño gráfico surgido en esta época fue el conocido como De Stijl o neoplasticismo. Nace en Holanda, en el año 1917, luego de que Theo Van Doesburg volviera de una temporada en el servicio militar. Esta vanguardia comenzaría en el campo de la pintura llevando la abstracción de los elementos hasta su máxima expresión, a tal punto que su lenguaje solo consistiría en rectángulos, cuadrados y líneas, junto con una acotadísima paleta cromática, solo colores primarios puros, negro y blanco. Los integrantes del movimiento estudiaron detalladamente la proporción de la forma, lograron la eliminación de todos los elementos curvos y diagonales, estudiaron la estructuración y las particiones del campo y la definición de zonas, todo esto desde una perspectiva lógica y matemática. Podemos ver su exploración en una variedad de piezas.

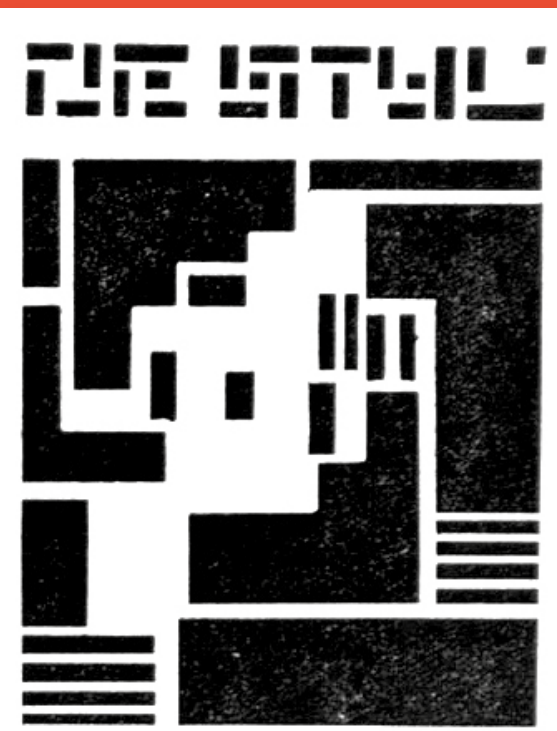

MAANDBLAD VOOR DE MO. DERNE BEELDENDE VAKKEN REDACTIE THEO VAN DOES. BURG MET MEDEWERKING VAN VOORNAME BINNEN. EN BUITENLANDSCHE KUNSTE. NAARS. UITGAVE $X$. HARMS TIEPEN TE DELFT IN 1917. 
A diferencia de los demás movimientos de la época, que reaccionaban de una manera u otra a la gran guerra y el clima hostil que vivía Europa, este movimiento consideraba que la realidad en la que vivían funcionaria como un depurador, que arrasaría con un antiguo paradigma para dar paso a las nuevas ideas. A su entender, una era de colectivismo, objetividad y universalidad se avecinaban.

Estos aires de cambio inundaron las producciones de De Stjil y sus artistas más consagrados buscaron dentro de sus diseños el mayor grado de objetividad y claridad. Antes de ahondar en el diseño editorial propiamente dicho, cabe destacar que la experimentación de Theo VAn Doesburg llegó al campo del diseño tipográfico. Él produjo un alfabeto construido sobre una rigurosa base cuadrada, razón por la que eliminó todos los aspectos diagonales y curvos propios de los caracteres. Esta decisión le costó la distinción eficiente entre caracteres (que resultaron todos muy parecidos entre sí), la disminución de la legibilidad y las posibilidades de utilizarla en cuerpos reducidos o en publicaciones muy extensas. Sin embargo, su singularidad la vuelve fácilmente identificable y es posible utilizarla en cuerpos grandes a fin de generar un efecto en una composición o una marca (ver ejemplo de alfabeto).
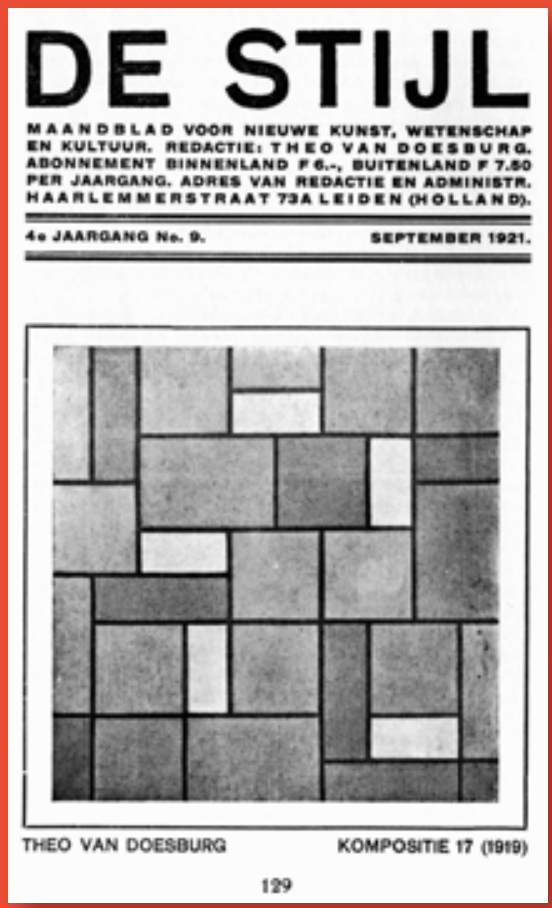

En el campo del diseño editorial, contaban con su propia publicación mensual a cargo de VAN DoesbURG, la revista De Stjil. Este era el espacio por medio del que promovían sus investigaciones y logros.

En esta portada se aplica y se interviene el alfabeto de VAN Doesburg a modo de marca o identificador solo en el sector del título, pero para conservar la legibilidad de la pieza, la caja
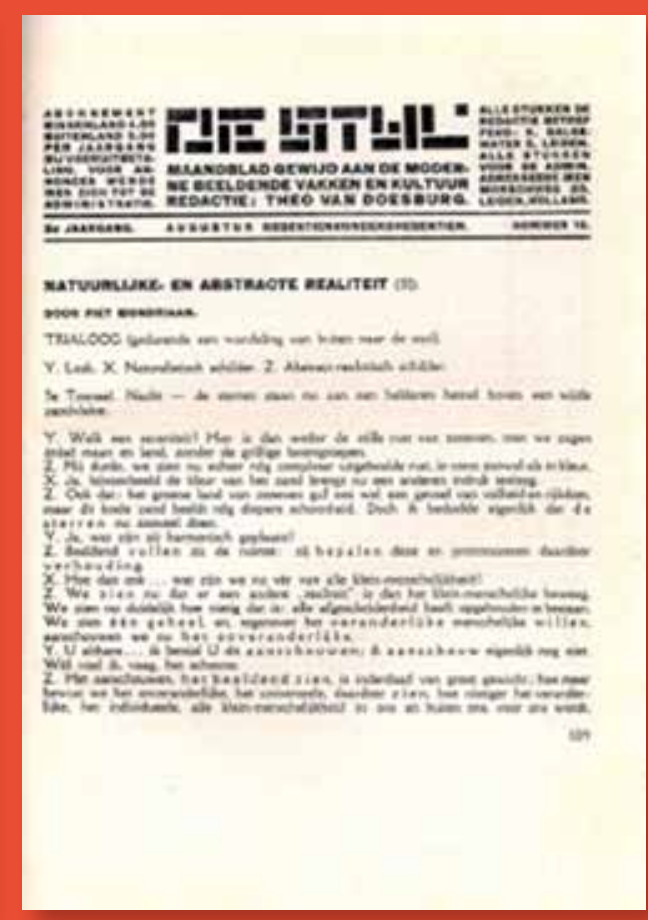

Revista De Stijl, 1917

de texto inferior utiliza otra tipografía sans serif más apta para la lectura. Estructuralmente la pieza puede dividirse en tres porciones horizontales, una zona más pequeña asignada al título, una mayor asignada para la imagen de cada número y por último un espacio para una caja de texto por debajo de la imagen, de un tamaño intermedio. Las tapas en su mayoría respetan esta misma estructura, variando entre una división de dos o tres porciones.

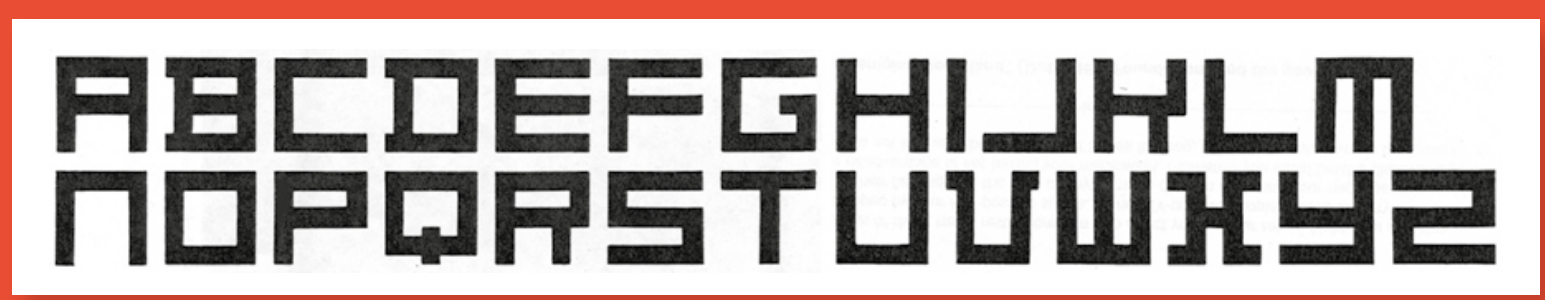


En esta primera página de la revista es posible observar una zonificación muy clara, al igual que en la portada, que cuenta con un logotipo en la parte superior de la página (en este caso está más elaborado, ya que pertenece a un número posterior de la revista) y en otro espacio el contenido de la nota. Dentro de este último sector es posible identificar con facilidad un título y subtítulo que están trabajados en caja alta, en bold, aspectos que los unifican, pero a la vez están compuestos en cuerpos distintos para hacer una diferencia entre ambos. La distribución y dimensión de las cajas es constante a lo largo de los distintos números.

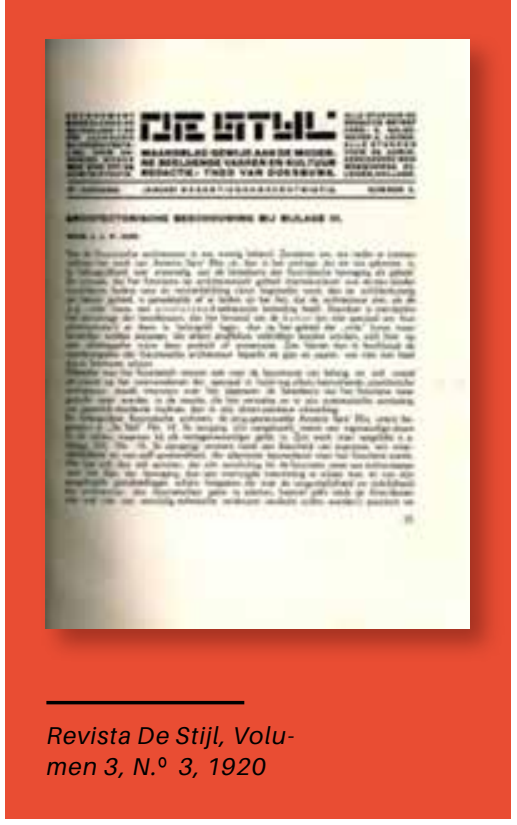

\section{CONCLUSIÓN}

Luego de haber recorrido, investigadoyanalizado la producción editorial europea en los primeros años del siglo XX y su contexto, es posible observar grandes cambios respecto de lo producido anteriormente. En primer lugar, existen notables modificaciones en el paradigma que predomina; lentamente se pasa del orden riguroso al caos (como es posible observar en las producciones dadaístas), para regresar luego al orden recuperando lo mejor que el caos pudiera brindar. Se toma de las desordenadas propuestas futuristas la expresividad tipográfica, y se la aplica luego para generar niveles de lectura dentro de una página, o el uso desmedido de líneas y misceláneas que proponeel dadaísmo, a fin de darle un sentido a la página y ordenar su lectura. Otro gran cambio de paradigma se relaciona con el abandono de las funciones nacionalistas de la tipografía antigua, al diseñar fuentes que tienen rasgos universales y son pensadas en función de las necesidades que deben cubrir para ser aplicadas en cualquier lugar. Es así que la propuesta inicialmente popularizada por el constructivismo de eliminar el serif para facilitar la lectura y hacerla más sencilla para quienes tenían dificultades, además de proponer una comunicación clara y efectiva, se esparció luego en el campo del diseño.

La separación de contenidos dentro de una misma página se hace ver fuertemente en este momento; por ejemplo, en las páginas de la revista Merz o Der Dada, donde el cambio de orientación, el cambio de variable o cuerpo diferencian de manera clara los diversos contenidos. En este momento se comienza a experimentar con el paginado como un elemento compositivo más allá de la regla, con el que se puede interactuar buscando formas creativas de resolverlo, como se puede ver en la revista Merz o en las composiciones de EL LIZZITZKY.

La forma de ordenar los contenidos dentro de la página cambia en este momento, pasa de contener una sola gran caja en la que se incluyen todos los elementos a contener dos o tres columnas, como se observa en Los Ismos del Arte; o una serie de cajas independientes entre sí, como es posible ver en las propuestas dadaístas. Se logra una primera aproximación a la situación de doble página, donde el contenido que es compartido por las dos páginas centrales debe leerse de forma conjunta.

Todos los cambios que se producen durante el período marcan un gran avance en el campo del diseño editorial y cambian completamente la construcción de las páginas, los elementos que las integran y su forma de ser leidas. Estas novedades marcaron una época, una forma de pensar, y crearon fuertes parámetros de diseño que han trascendido el tiempo y están vigentes hasta nuestros días.

\section{BIBLIOGRAFIA}

AYNSLEY, J. (2001). Pioners of modern graphic design. Londres: Octopus publishing.

BLACKWELL L. (2013). 20 centurytype and beyond. Londres: Laurence King. FLASK, D. (2010). History of graphic design. http://www.designishistory.com/ LEWIS, J. (1963). Typography, basic principles. Londres: Studio Books.

MEGGS, P. B. (1991). Historia del diseño gráfico. México: RM Verlag.

SATUÉ, E. (2012). El diseño gráfico: desde los orígenes hasta nuestros días. Madrid: Alianza Editorial.

SPENCER, H. (1960). Pioneros de la tipografía moderna. Barcelona: Gustavo Gili. 